\title{
Long-Term Treatment with Low Doses of Methamphetamine Promotes Neuronal Differentiation and Strengthens Long-Term Potentiation of Glutamatergic Synapses onto Dentate Granule Neurons
}

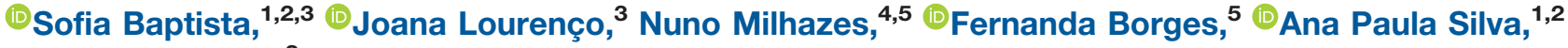 \\ and Alberto Bacci ${ }^{3}$
}

DOI:http://dx.doi.org/10.1523/ENEURO.0141-16.2016

\begin{abstract}
${ }^{1}$ Institute of Pharmacology and Experimental Therapeutics, Faculty of Medicine, University of Coimbra, $3000-548$ Coimbra, Portugal, ${ }^{2}$ Institute for Biomedical Imaging and Life Sciences, Faculty of Medicine, University of Coimbra, 3000-548 Coimbra, Portugal, ${ }^{3}$ Sorbonne Universités, Université Pierre et Marie Curie, Unité Mixte de Recherche (UMR) S 1127, Institut National de la Santé et de la Recherche Médicale U 1127, Centre National de la Recherche Scientifique UMR 7225, and Institut du Cerveau et de la Moelle épinière, 75013 Paris, France, ${ }^{4}$ Institute of Health Sciences-North, 4585-116 Gandra, Portugal, ${ }^{5}$ Department of Chemistry and Biochemistry, Faculty of Sciences, Centro de Investigação em Química da Universidade do Porto, 4169-007 Porto, Portugal
\end{abstract}

\begin{abstract}
Methamphetamine (METH) is a psychostimulant, affecting hippocampal function with disparate cognitive effects, which depends on the dose and time of administration, ranging from improvement to impairment of memory. Importantly, in the United States, METH is approved for the treatment of attention deficit hyperactivity disorder. Modifications of long-term plasticity of synapses originating from the entorhinal cortex onto dentate granule cells (DGCs) have been proposed to underlie cognitive alterations similar to those seen in METH users. However, the effects of METH on synaptic plasticity of the dentate gyrus are unknown. Here, we investigated the impact of long-term administration of METH $(2 \mathrm{mg} / \mathrm{kg} / \mathrm{d})$ on neurogenesis and synaptic plasticity of immature and mature DGCs of juvenile mice. We used a mouse model of neurogenesis (the G42 line of GAD67-GFP), in which GFP is expressed by differentiating young DGCs. METH treatment enhanced the differentiation of GFP ${ }^{+}$cells, as it increased the fraction of $\mathrm{GFP}^{+}$cells expressing the neuronal marker NeuN, and decreased the amount of immature DGCs coexpressing doublecortin. Interestingly, METH did not change the magnitude of long-term potentiation (LTP) in more immature neurons, but facilitated LTP induction in more differentiated GFP $^{+}$and strengthened plasticity in mature GFP ${ }^{-}$DGCs. The METH-induced facilitation of LTP in GFP ${ }^{+}$neurons was accompanied with spine enlargement. Our results reveal a specific action of long-term use of METH in the long-term plasticity of excitatory synapses onto differentiating DGCs and might have important implications toward the understanding of the synaptic basis of METH-induced cognitive alterations.
\end{abstract}

Key words: ADHD; dentate gyrus; methamphetamine; neurogenesis; synaptic plasticity

\section{Significance Statement}

Methamphetamine (METH) abuse/misuse can induce memory deficits, but controlled drug prescription is approved by the Food and Drug Administration for the treatment of attention deficit hyperactivity disorder. Additionally, dentate gyrus (DG) neurogenesis contributes to the formation and consolidation of new memories. We therefore studied the effects of $7 \mathrm{~d}$ exposure to a low dose of METH in DG neurogenesis as well as its impact in synaptic plasticity. We observed that METH accelerated immature neuron differentiation and facilitates LTP in more differentiated immature neurons and mature DGCs. These effects might be the synaptic correlate of some of the METH-induced memory alterations. 


\section{Introduction}

Methamphetamine (METH) is a psychostimulant that is commonly known as a highly addictive drug of abuse, having a negative impact on the CNS (Gonçalves et al., 2014). Indeed, many studies have indicated that METH abuse induces deficits in working memory (Simon et al., 2000) and decreases hippocampal volume, which can be correlated with poorer word recall test results (Thompson et al., 2004). In rodents, hippocampal-dependent memory performance may depend on the dose of METH administered. Indeed, a high dose (30 mg/kg, i.p.) can induce memory deficits (Simões et al., 2007; Gonçalves et al., 2012), whereas a lower dose (1 mg/kg, i.p.) can improve spatial memory consolidation (Cao et al., 2013). Importantly, METH is approved by the U.S. Food and Drug Administration for the treatment of attention deficit hyperactivity disorders (ADHDs), under the commercial name Desoxyn, with an effective dose of $20-25 \mathrm{mg}$.

Adult neurogenesis occurs throughout life in the subgranular zone of the dentate gyrus (DG) and the subventricular zone (Lledo et al., 2006), and there is a strong link between hippocampal neurogenesis and memory performance, as immature DG neurons are preferentially activated and recruited into spatial memory networks (Kee et al., 2007; Garthe et al., 2009). Indeed, DG plasticity can be induced by stimulating the perforant path of the molecular layer, by tetanic, patterned, high-frequency or theta-burst stimulations (TBSs) that can trigger long-term potentiation (LTP) onto dentate granule cells (DGCs; Bliss and Lømo, 1973; Richter-Levin et al., 1994; Panja et al., 2014). It is widely believed that a long-lasting change in synaptic function is the cellular basis of learning and memory (Malinow and Malenka, 2002), and the most characterized examples of synaptic plasticity are LTP or

Received May 31, 2016; accepted June 14, 2016; First published June 23, 2016.

The authors declare no competing financial interests.

Author contributions: S.B., A.P.S., and A.B. designed research; N.M. and F.B. contributed unpublished reagents/analytic tools; S.B., J.L., and A.B. analyzed data; S.B. and A.B. wrote the paper.

This work was supported by fellowship SFRH/BD/63773/2009 from the Foundation for Science and Technology, Portugal; was cofinanced by Quadro de Referência Estratégica Nacional (S.B.), strategic project UID/ NEU/04539/2013 (A.P.S.), and the European Research Council (ERC) under the 7th Framework Programme for the European Community (FP7/20072013)/ERC Grant agreement No. 200808); “Investissements d'avenir" ANR10-IAIHU-06; Agence Nationale de la Recherche (ANR-13-BSV4-0015-01), Fondation Recherche Médicale (Equipe FRM DEQ20150331684), and a grant from the Institut du Cerveau et de la Moelle épinière (Paris) (A.B.). A.B. is supported by a 2014 NARSAD Independent Investigator Grant from the Brain and Behavior Research Foundation.

Acknowledgements: We thank Carolina Cabezas for help with immunohistochemistry analysis, and Geeske M. van Woerden for help with analysis of dendritic spines.

Correspondence should be addressed to Alberto Bacci, ICM-Institut du Cerveau et de la Moelle épinière, CNRS UMR 7225-INSERM U1127-UPMC-P6 UMR S 1127, Groupe Hospitalier Pitié Salpêtrière, 47 Boulevard de l'Hopital, 75013 Paris, France. E-mail: alberto.bacci@icm-institute.org.

DOI:http://dx.doi.org/10.1523/ENEURO.0141-16.2016

Copyright (C) 2016 Baptista et al.

This is an open-access article distributed under the terms of the Creative Commons Attribution 4.0 International, which permits unrestricted use, distribution and reproduction in any medium provided that the original work is properly attributed. long-term depression of glutamatergic neurotransmission in the CA1 and DG areas of the hippocampus. Likewise, recent evidence causally linked LTP with learning and memory in several brain areas, including the DG (Zeng et al., 2001; Whitlock et al., 2006; Nabavi et al., 2013, 2014; Gruart et al., 2015; Ryan et al., 2015). It is known that medial perforant path (MPP)-DG synapses are crucial for spatial learning, context-dependent learning, and episodic memory (Hargreaves et al., 2005). Indeed, MPP, as opposed to lateral perforant path, is strongly involved in spatial information processing (Hargreaves et al., 2005).

Some evidence indicates that neurogenesis can be affected by METH, depending on the dose and frequency of exposure. Indeed, self-administration with intermittent access to METH, which mimics a human recreational use, increases DGC proliferation and differentiation (Mandyam et al., 2008). Conversely, both short- and long-term use (daily access) decrease proliferation and differentiation followed by a reduced number of DGCs (Mandyam et al., 2008). In vitro studies also showed that METH induces cell cycle arrest in DG stem cells and impairs their selfrenewal, resulting in their differentiation into the neuronal phenotype (Baptista et al., 2014). Also, under differentiation conditions, a nontoxic dose of METH can impair the maturation of DG stem/progenitor cells (Baptista et al., 2012). In this scenario, it is crucial to understand whether low doses of METH affect the functional properties of immature and mature DG cells. In the present work, we explored the effects of long-term (7 d) METH administration at low doses $(2 \mathrm{mg} / \mathrm{kg})$ on DG neurogenesis, and its influence on the synaptic plasticity of both immature and mature neurons. It is noteworthy that the METH injection protocol used in the present work mimics ADHD treatment. We found that METH accelerated the maturation of immature neurons, and strengthened LTP at more mature differentiating stages and fully developed DGCs. Our results indicate that long-term administration of low doses of METH strengthens synaptic plasticity at a specific maturation stage of DGCs and could therefore affect memory performance.

\section{Materials and Methods}

\section{Mice}

Experimental procedures followed national and European (2010/63/EU) guidelines, and have been approved by AP Silva institutional review boards. All efforts were made to minimize suffering and reduce the number of animals used in the procedures. Experiments were performed on G42 (GAD1-EGFP) mice, which were obtained from The Jackson Laboratory (Jax mouse line, Tg(Gad1EGFP)G42Zjh; mouse strain datasheet \#007677). In this mouse line, GFP ${ }^{+}$cells are parvalbumin-expressing, fastspiking interneurons in the neocortex (Chattopadhyaya et al., 2004) and immature DGCs of the hippocampus with a transient GABAergic phenotype (Cabezas et al., 2012, 2013). G42 mice were continuously backcrossed on a C57BL/6 background and were weaned at postnatal day 21 (P21), and only males were used for the experiments. Although hydrocephaly has been described in this mouse 
strain (https://www.jax.org/strain/007677), all hydrocephalus animals were discarded from experiments.

\section{METH injection protocol}

METH was synthesized at the Organic Chemistry Department, Faculty of Pharmacy, University of Porto, Porto, Portugal, and was dissolved in $0.9 \% \mathrm{NaCl}$ at a concentration of $0.8 \mathrm{mg} / \mathrm{ml}$. P20-P24 G42 mice were injected with $2 \mathrm{mg} / \mathrm{kg} \mathrm{METH}$, or saline solution (intraperitoneally), every day for $7 \mathrm{~d}$. Taking into consideration the duality of METH use (drug of abuse vs ADHD treatment), the protocol used here aimed at mimicking METH administration for ADHD treatment (the usual effective dose is $20-25 \mathrm{mg}$ daily), in contrast to the already well known impact of METH abuse. Immunohistochemical, morphological, and electrophysiological experiments were performed $24 \mathrm{~h}$ after the last injection.

\section{Immunohistochemistry}

Mice were anesthetized with ketamine $(80 \mathrm{mg} / \mathrm{kg}$, i.p.; Imalgène) and xylazine (20 mg/kg, i.p.; Rompun, Bayer), transcardially perfused with $4 \%$ paraformaldehyde (PFA), and cryopreserved in $30 \%$ sucrose. Brains were horizontally cut in $40-\mu \mathrm{m}$-thick slices in a cryotome (Microm HM450). Slices were rinsed with PBS and blocked in $10 \%$ $\mathrm{BSA}$ and $0.3 \%$ Triton for $2 \mathrm{~h}$ at room temperature. Slices were incubated with the following primary antibodies overnight at $4^{\circ} \mathrm{C}$ : chicken anti-green fluorescent protein (1:1000; Millipore); rabbit anti-doublecortin (DCX; 1:2000; Cell Signaling Technology); and mouse anti-NeuN (1:250; Millipore). Slices were incubated with the respective secondary antibodies for $3.5 \mathrm{~h}$ at room temperature, as follows: donkey anti-chicken IgG Cy2 (1:500); donkey anti-rabbit IgG Cy3 (1:600); and Alexa Fluor 647 donkey anti-mouse (1:400; all from Jackson ImmunoResearch). Slices were mounted in Fluoromount-G (Southern Biotech; Cabezas et al., 2013). Images were acquired on an inverted confocal microscope (SP2, Leica) and were obtained from stacks of $10-17$ sections, $2.5 \mu \mathrm{m}$ apart, using a $63 \times / 1.32$ numerical aperture objective. Images were acquired from four slices per animal of five saline- or METH-treated mice. Cell counts were calculated using ImageJ software. Results are expressed as the percentage of total GFP cells expressing DCX and/or NeuN.

\section{In vitro slice preparation and electrophysiology}

G42 mice aged P28-P32 were anesthetized with isoflurane (Sigma-Aldrich) and were immediately decapitated. Brains were quickly removed into ice-cold cutting solution containing the following (in $\mathrm{mm}$ ): 248 sucrose, 26 $\mathrm{NaHCO}_{3}, 1 \mathrm{KCl}, 1 \mathrm{CaCl}_{2}, 5 \mathrm{MgCl}_{2}$, and 10 glucose (all from Sigma-Aldrich). The 350- $\mu \mathrm{m}$-thick horizontal slices were then obtained using a vibratome (VT 1200 S, Leica) and transferred to an incubating chamber containing artificial CSF solution (ACSF) as follows (in mM): $126 \mathrm{NaCl}$, $2.5 \mathrm{KCl}, 1.25 \mathrm{NaH}_{2} \mathrm{PO}_{4}, 26 \mathrm{NaHCO}_{3}, 2 \mathrm{CaCl}_{2}, 1 \mathrm{MgCl}_{2}$, and 16 glucose (all from Sigma-Aldrich), bubbled with $95 \% \mathrm{O}_{2} / 5 \% \mathrm{CO}_{2}$ at $34^{\circ} \mathrm{C}$ for $30 \mathrm{~min}$, followed by incubation at room temperature for at least $1 \mathrm{~h}$ before recording. Slices were then transferred to a submerged recording chamber, and neurons were visualized using infrared videomicroscopy in a microscope equipped with epifluorescence. Recordings were performed at $32^{\circ} \mathrm{C}$ in the continuous presence of the $\mathrm{GABA}_{A}$ receptor $\left(G A B A_{A} R\right)$ antagonist gabazine $(10 \mu \mathrm{M})$. Microelectrodes with 3-4 $\mathrm{M} \Omega$ tip resistance were pulled from borosilicate glass capillaries [World Precision Instruments (WPI)] using a Flaming/Brown Micropipette puller P-97 (Sutter Instruments). Intracellular solution consisted of the following (in $\mathrm{mm}$ ): 130 potassium gluconate, $10 \mathrm{KCl}, 10$ HEPES, 2 $\mathrm{MgCl}_{2}$, 5 phosphocreatine, 4 MgATP, 0.3 NaGTP, and 0.2 EGTA (all from Sigma-Aldrich), pH 7.3, with an osmolarity of $\sim 290 \mathrm{mOsm}$. DGCs were whole cell, patch clamped, and were recorded both in current- and voltage-clamp modes. Signals were amplified with a MultiClamp 700B patch-clamp amplifier, sampled at $10 \mathrm{kHz}$, and filtered at $4 \mathrm{kHz}$ (Molecular Devices). Data were analyzed using the PClamp 10 software package (Molecular Devices) and GraphPad Prism software. GFP ${ }^{+}$and GFP $^{-}$cells were characterized in current-clamp mode. Action potential (AP) firing was evoked by injecting 1-s-long depolarizing steps of increasing amplitude, starting at $-25 \mathrm{pA}$ and with increments of $10 \mathrm{pA}$. For LTP experiments, DGCs were recorded in voltage-clamp mode at a holding potential of $-70 \mathrm{mV}$. A bipolar stimulating electrode, fabricated from a theta capillary (WPI), was filled with ACSF and placed in the middle third of the molecular layer in order to orthodromically stimulate the MPP. EPSCs were evoked by short $(0.2 \mathrm{~ms})$ pulses at $5 \mathrm{~V}$ using an isolation unit (Isoflex, A.M.P.I), triggered by the digital output of the digitizer (Digidata 1440, Molecular Devices) and controlled by PClamp version 10. LTP was induced by applying a TBS paradigm consisting of five bursts of five extracellular stimulations at $100 \mathrm{~Hz}$, repeated at $5 \mathrm{~Hz}$, and paired with postsynaptic depolarization at $-30 \mathrm{mV}$. These bursts were delivered 16 times at $0.1 \mathrm{~Hz}$ (Bowden et al., 2012). Series resistance was continuously monitored, and recordings were discarded if it was $>30 \mathrm{M} \Omega$ or changed $>20 \%$.

\section{Morphological analysis}

Cells were filled with neurobiotin $(3 \mathrm{mg} / \mathrm{ml}$; Vector Laboratories) added to the intracellular solution. After fixation with 4\% PFA followed by PBS rinses, cells were permeabilized in 2\% Triton in PBS for $1 \mathrm{~h}$ and then incubated for $2 \mathrm{~h}$ with $\mathrm{ABC}$ reagent (avidin and biotinylated horseradish peroxidase complex; Vector Laboratories). Slices were rinsed in PBS $(2 \times 10 \mathrm{~min}, 1 \times 15 \mathrm{~min}$ and $1 \times 1 \mathrm{~h})$ and reacted with 3,3'-diaminobenzidine (Vector Laboratories) until the stain was visualized. Slices were mounted in $85 \%$ glycerol (Sigma-Aldrich) in PBS. Neurons were reconstructed using the Neurolucida software (Microbrightfield) using a $40 \times$ objective. Differential interference contrast images were acquired with a macroscope (AZ100, Nikon) from stacks of 11 sections, $2 \mu \mathrm{m}$ apart, using a $5 \times$ objective. Neurobiotin-filled neurons were also visualized by fluorescence upon streptavidin aminimethylcoumarin (Jackson ImmunoResearch) staining, and images were acquired by confocal microscopy, as mentioned above. Spine density and area were determined using ImageJ. Spine density was assessed by counting the number of 

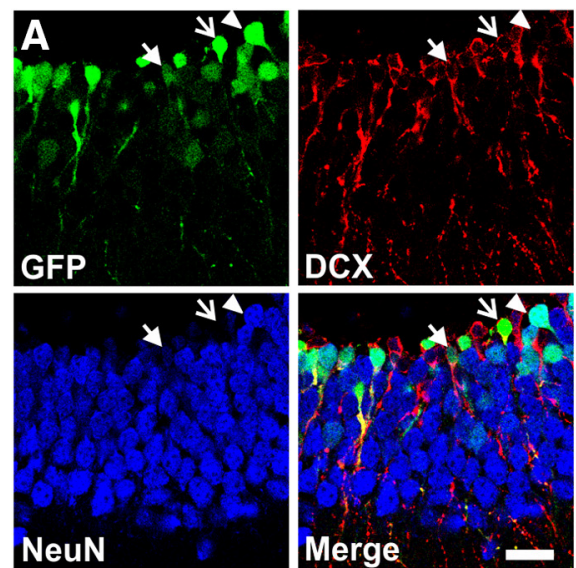

B
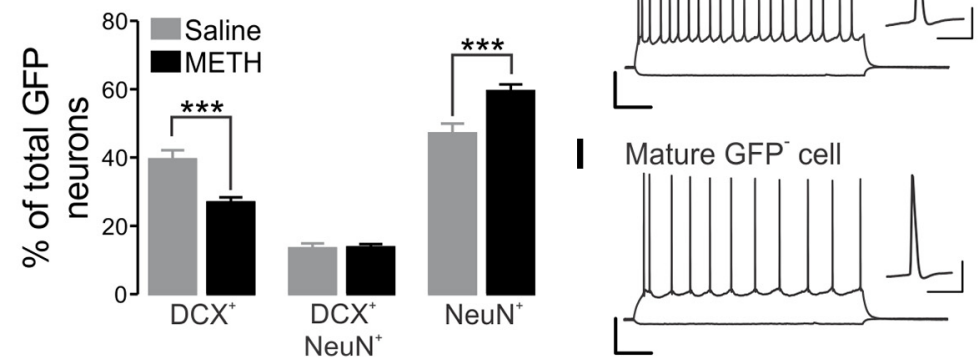

E Group 2 GFP $^{+}$cell

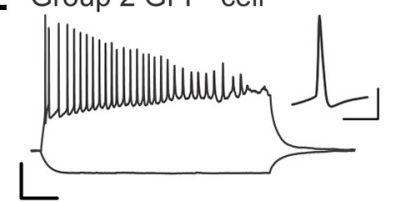

G Group 3 GFP $^{+}$cell
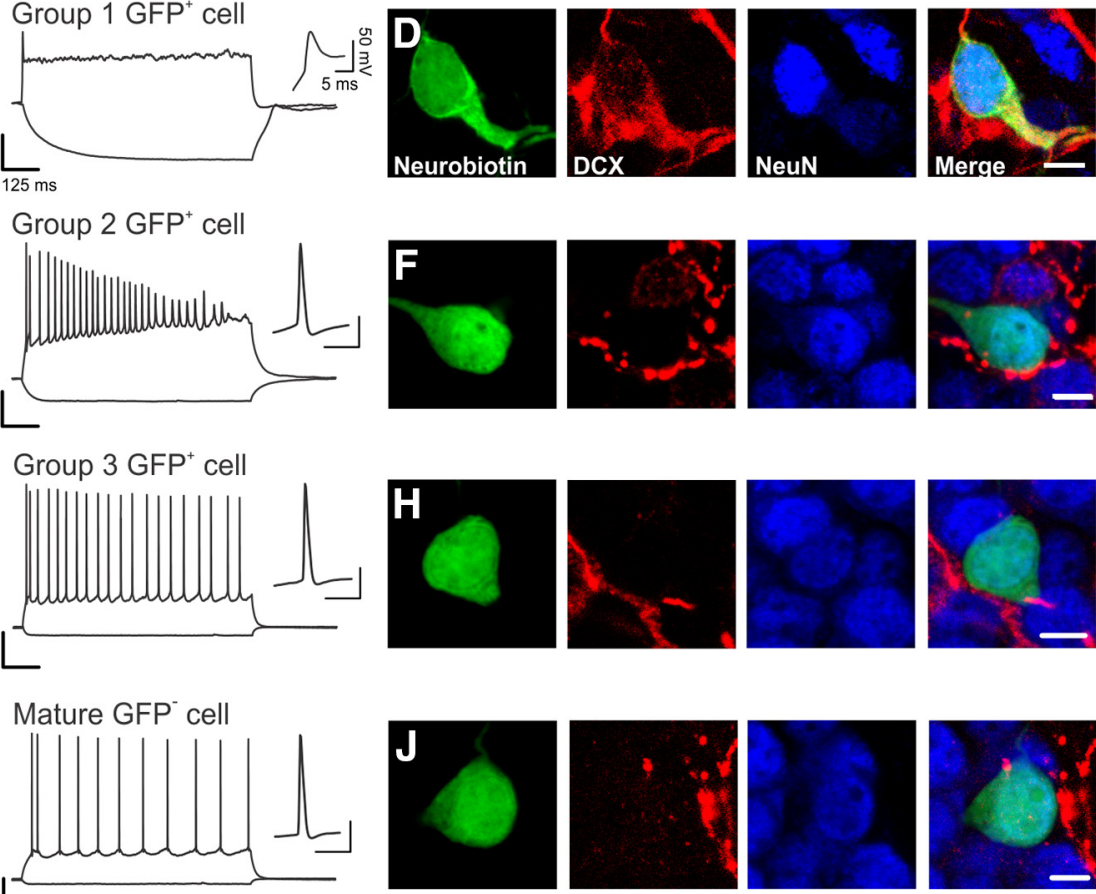

Figure 1. METH enhances the differentiation of immature DG neurons. $\boldsymbol{A}$, Representative confocal images exhibiting the different phenotypes of immature GFP ${ }^{+}$DGCs. Open arrows, GFP ${ }^{+} / \mathrm{DCX}^{+}$cells; closed arrows, $\mathrm{GFP}^{+} / \mathrm{DCX}^{+} / \mathrm{NeuN}^{+} ; \mathrm{arrowheads} \mathrm{GFP}^{+} /$ $\mathrm{NeuN}^{+}$. Scale bar, $50 \mu \mathrm{m}$. B. Bar graph illustrating the effect of METH in GFP ${ }^{+}$cell phenotype. Data are expressed as a percentage of GFP ${ }^{+}$cells \pm SEM from four horizontal slices/animal of at least five animals per condition. $* * * p<0.001$, significantly different from saline using Mann-Whitney post hoc test. $\mathbf{C}-\mathbf{I}$, Current-clamp traces showing that GFP ${ }^{+}$cells exhibit different AP firing profile patterns identified as group 1, 2, 3, and mature cells $(\boldsymbol{C}, \boldsymbol{E}, \boldsymbol{G}, \boldsymbol{I})$, respectively, and the respective phenotype characterization $(\boldsymbol{D}, \boldsymbol{F}, \boldsymbol{H}$, and $\boldsymbol{J})$. Cells were analyzed from at least three mice. Scale bar, $5 \mu \mathrm{m}$.

spines divided by the length of a dendritic segment. Spine areas were determined by drawing individual regions of interest (ROIs) outlining spine heads and necks, and the area of each ROI was then measured.

\section{Data analysis}

Statistical significance was assessed using one-way ANOVA followed by Kruskal-Wallis test and by Dunn's multiple comparison test or Mann-Whitney post hoc test, as indicated in the figure legends. Data are expressed as the mean \pm SEM, and the statistical significance level was set for $p<0.05$. Cumulative distributions were compared using the Kolmogorov-Smirnov test.

\section{Results}

\section{Methamphetamine accelerates immature dentate granule cell maturation}

G42 mice were used as a model of DG neurogenesis, because GFP expression is transient and specific for immature DGCs (Cabezas et al., 2013). We performed immunohistochemical staining of 28-32-d-old mice, consistent with previous reports (Cabezas et al., 2012, 2013), and we found that $\mathrm{GFP}^{+}$neurons corresponded to immature DGCs at different stages of neuronal maturation. DGCs expressed DCX alone (Fig. 1A, open arrows), coexpressed DCX and NeuN (Fig. 1A, filled arrows), or expressed NeuN (Fig. 1A, arrowheads). Long-term administration of METH (2 mg/kg/d, i.p., for $7 \mathrm{~d}$ ) decreased the number of $\mathrm{GFP}^{+}$cells expressing only DCX (saline, $39.42 \pm 2.75 \%$ of total GFP cells; METH, $26.85 \pm 1.54 \%$ of total GFP cells; $p<0.001$ ) and increased the number of GFP $^{+}$cells that were positive for NeuN (saline, $47.12+$ $2.84 \%$ of total GFP cells; METH, $59.42 \pm 1.98 \%$ of total GFP cells; $p<0.001$; Fig. 1B). METH treatment did not interfere with $\mathrm{GFP}^{+}$DGCs coexpressing DCX and NeuN (saline, $13.46 \pm 1.43 \%$ of total GFP cells; METH, $13.72 \pm$ $0.95 \%$ of total GFP cells; Fig. 1B). Additionally, METH decreased the total number of $\mathrm{GFP}^{+}$-expressing DCX cells, regardless of whether they also expressed NeuN (saline, $53.27 \pm 3.07 \%$ of total GFP; METH, $40.65 \pm$ $2.08 \%$ of total GFP; $p<0.05)$. In contrast, it increased the total number of $\mathrm{GFP}^{+}$cells expressing NeuN, regardless of whether they also expressed DCX (saline, $60.28 \pm$ $2.97 \%$ of total GFP; METH, $73.09 \pm 1.62 \%$ of total GFP; $p<0.05)$. Importantly, METH did not change the total number of GFP ${ }^{+}$cells in each horizontal section of the DG (density of GFP ${ }^{+}$DGCs: saline, $1.09 \pm 0.35 \%$ cells $/ \mathrm{mm}^{2}$; METH, $1.53 \pm 0.47 \%$ cells $/ \mathrm{mm}^{2} ; p>0.05 ; n=4$ mice per group).

We then performed whole-cell current-clamp recordings from several GFP ${ }^{+}(n=115$ cells $)$ and $\mathrm{GFP}^{-}(n=$ 
Table 1. Action potential waveform and membrane properties values of GFP ${ }^{+}$DG neurons

\begin{tabular}{|c|c|c|c|c|c|c|}
\hline \multirow[b]{3}{*}{ AP peak $(\mathrm{mV}) *$} & \multicolumn{2}{|c|}{ Group 1} & \multicolumn{2}{|c|}{ Group 2} & \multicolumn{2}{|c|}{ Group 3} \\
\hline & Saline & METH & Saline & METH & Saline & METH \\
\hline & $-0.97 \pm 1.70$ & $-0.72 \pm 4.28$ & $34.59 \pm 2.26$ & $40.95 \pm 1.70$ & $45.27 \pm 1.72$ & $46.18 \pm 2.50$ \\
\hline AP amplitude $(\mathrm{mV}) *$ & $29.38 \pm 3.10$ & $30.25 \pm 5.99$ & $80.57 \pm 3.86$ & $85.83 \pm 2.81$ & $95.24 \pm 1.47$ & $94.43 \pm 2.94$ \\
\hline Half-width (ms)* & $3.38 \pm 0.45$ & $3.35 \pm 0.69$ & $0.98 \pm 0.10$ & $0.79 \pm 0.06$ & $0.85 \pm 0.04$ & $0.79 \pm 0.05$ \\
\hline $\mathrm{C}_{\mathrm{m}}(\mathrm{pF}) *$ & $21.66 \pm 0.77$ & $19.96 \pm 1.18$ & $40.02 \pm 3.21$ & $42.39 \pm 7.32$ & $56.00 \pm 3.13$ & $49.96 \pm 3.22$ \\
\hline $\mathrm{R}_{\text {in }}(\mathrm{G} \Omega) *$ & $2.32 \pm 0.16$ & $2.35 \pm 0.18$ & $0.68 \pm 0.11$ & $0.92 \pm 0.15$ & $0.38 \pm 0.03$ & $0.36 \pm 0.03$ \\
\hline
\end{tabular}

Values are given as the mean \pm SEM. METH induced no effect in all parameters analyzed. $\mathrm{C}_{\mathrm{m}}$, membrane capacitance; $\mathrm{R}_{\mathrm{in}}$, input resistance; RMP, resting membrane potential.

*Significantly different, using Kruskal-Wallis test followed by Dunn's post hoc test or Bonferroni's post hoc test. Asterisks correspond to statistical signifi-

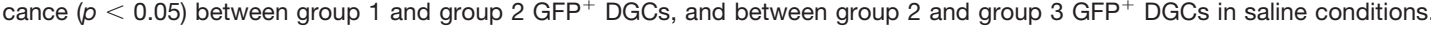

69 cells) DGCs, and we found three major different firing patterns in response to depolarizing current pulses (Fig. 1C,E,G,I). Group 1 neurons fired only single, small-amplitude APs, irrespective of the intensity of stimulation (Fig. 1C); group 2 neurons generated few APs during the depolarizing current step, with a diminishing AP amplitude (Fig. 1E); group 3 neurons exhibit a fully blown, repetitive AP firing pattern (Fig. 1G), more similar to mature GFP ${ }^{-}$neurons (Fig. 1/). Importantly, $\mathrm{GFP}^{+}$DG neurons belonging to groups 1-3 displayed significantly different values for passive membrane properties and action potential waveforms (Table 1). This was consistent with previously described functional changes of developing DG neurons (Mongiat et al., 2009; Cabezas et al., 2013).

DGCs were regularly filled with neurobiotin during electrophysiological experiments, and then immunolabeled with DCX and NeuN. Group $1 \mathrm{GFP}^{+}$cells expressed both DCX and NeuN (Fig. 1D), whereas both group 2 and $3 \mathrm{GFP}^{+}$cells expressed NeuN alone (Fig. $1 F, H)$. As expected, mature DGCs expressed NeuN (Fig. 1J). Overall, Group 1, 2, and 3 DGCs corresponded to $27 \%, 24 \%$, and $49 \%$ of our total recorded cells $(n=$ 74). Although METH treatment increased the number of NeuN-expressing DGCs, it did not change the incidence of finding group $1(25 \%), 2(31 \%)$, or $3(44 \%)$ cells in our recordings $(n=76$; data not shown; $p>$ 0.05). Importantly, METH treatment did not alter DGC excitability, measured as an AP waveform, and passive membrane properties in all groups (data not shown). Surprisingly, we could not find $\mathrm{GFP}^{+}$neurons expressing only DCX in these recordings, possibly due to undersampling during our electrophysiological recordings associated with immunohistochemistry characterization ( $n=36$ cells). It is likely that group 1 neurons encompass neurons expressing either DCX only or $\mathrm{DCX} / \mathrm{NeuN}$, and that they could be located nearby the subgranular zone. Indeed, DGCs expressing only DCX showed firing properties similar to our group 1 neurons (Lledo et al., 2006).

Overall, we found that $\mathrm{GFP}^{+}$cells in juvenile G42 mice correspond to differentiating newborn neurons at different stages of maturation and that METH treatment promoted DGC differentiation.

\section{Methamphetamine effects on synaptic plasticity in different DGCs groups}

Although some studies have pointed out that METH induces cognitive deficits (Simon et al., 2000), others showed that METH can improve memory performance (Cao et al., 2013; Silber et al., 2006). Also, the integration of immature neurons into pre-existent DG circuitry is known to have a prominent role in memory processes (Kee et al., 2007; Garthe et al., 2009). We therefore aimed at clarifying whether long-term treatment with a daily low dose of METH affects the synaptic plasticity of both immature and mature DG neurons.

$\mathrm{GFP}^{+}$and $\mathrm{GFP}^{-}$neurons were recorded in voltage clamp, in the continuous presence of the $\mathrm{GABA}_{A} R$ antagonist gabazine $(10 \mu \mathrm{M})$, and excitatory postsynaptic currents (EPSCs) were evoked by extracellular stimulation of the MPP. The stimulation of MPP was confirmed as EPSCs were strongly reduced after application of the selective $\mathrm{mGlu}_{2}$ receptor agonist DCG-IV, which was shown to be selectively expressed by MPP terminals (Chiu and Castillo, 2008; data not shown). Group 1 neurons showed few or no EPSCs (data not shown) and therefore could not be studied further. Group 2 cells were able to generate evoked EPSCs and showed robust LTP after TBS application (Fig. 2A). Indeed, the increase in synaptic strength was verified in both saline (baseline, $82.22 \pm 1.46 \mathrm{pA}$; last $5 \mathrm{~min}$ after TBS, $128.30 \pm 3.01 \mathrm{pA} ; p<0.001$, paired $t$ test; $n=7$ ) and METH (baseline, $70.21 \pm 3.22 \mathrm{pA}$; last $5 \mathrm{~min}$ after TBS, $128.70 \pm$ 6.27 pA; $p<0.001$, paired $t$ test; $n=8$; Fig. $2 A$ ). Both in saline and METH, EPSC amplitude increased when compared with the respective baseline values (Fig. 2B), but METH did not induce any effect on the magnitude of LTP in group $2 \mathrm{GFP}^{+}$cells ( $p>0.05$; Fig. $2 C$ ).

Surprisingly, group 3 cells consistently exhibited only a transient increase in EPSCs in response to TBS in salinetreated animals (Fig. 2D-F). This could not be considered as LTP, because it was not sustained for $>20 \mathrm{~min}$ (baseline, $96.21 \pm 11.39 \mathrm{pA}$; last $5 \mathrm{~min}$ after TBS, $109.80 \pm$ 17.25 pA; paired $t$ test; $n=12$ cells; Fig. $2 D$ ). Interestingly, METH treatment promoted the expression of a longlasting LTP in group 3 DGCs (EPSCs at baseline, $64.80 \pm$ $5.69 \mathrm{pA}$; EPSCs in the last 5 min after TBS, $105.20 \pm 9.42$ $\mathrm{pA} ; p<0.001$, paired $t$ test; $n=7$ cells), which were significantly different from those in the saline group $(p<$ 0.05 ; Fig. $2 E, F$ ). Finally, in mature neurons (not expressing 
A

Group 2

GFP $^{+}$cells

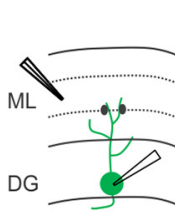

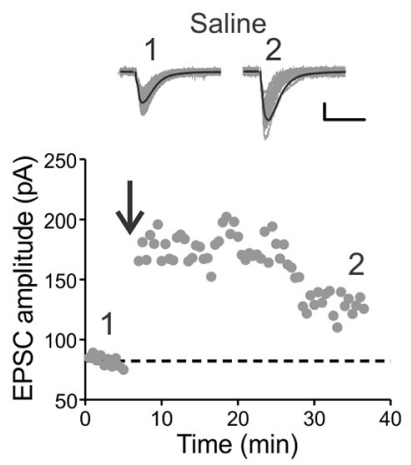
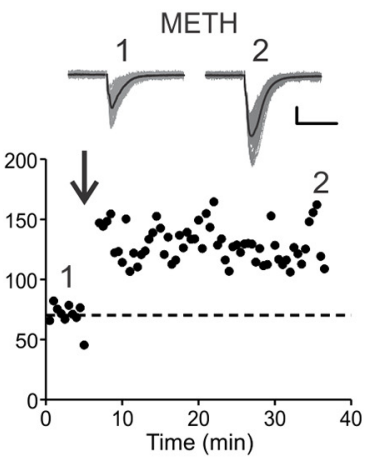

B

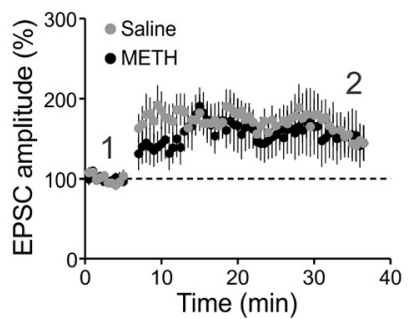

C

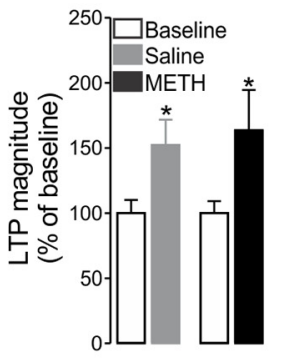

E

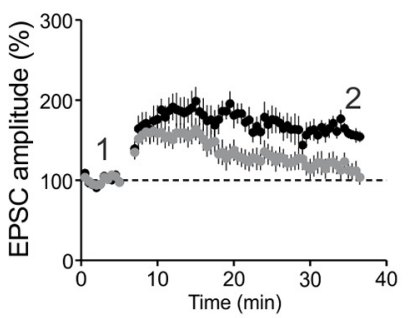

F

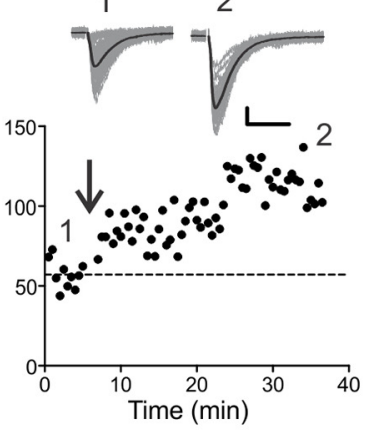

H

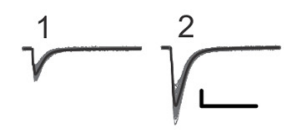

GFP- cells
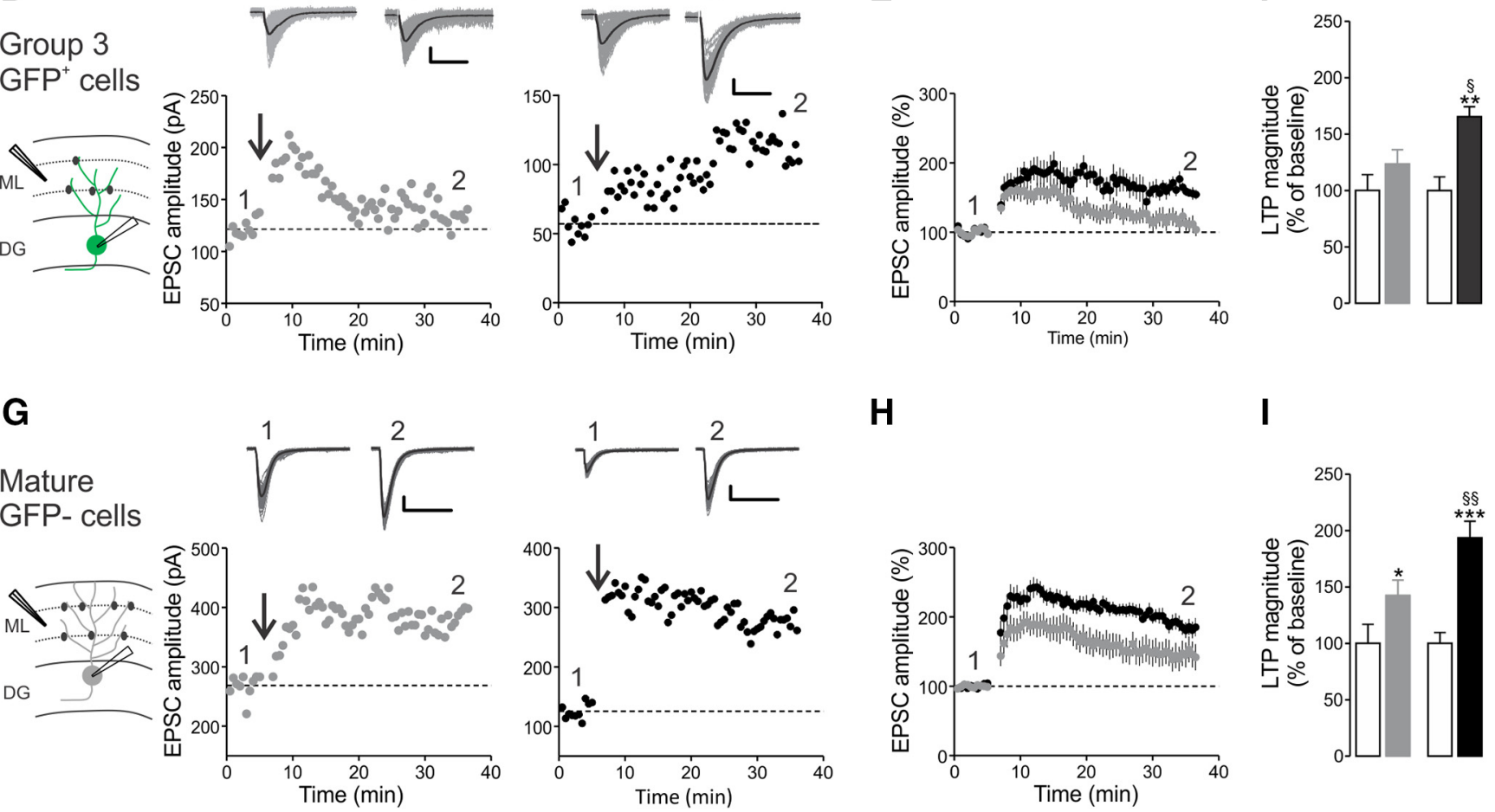

Figure 2. METH effects on LTP in differentiating GFP $^{+}$neurons and in mature DGCs. $\boldsymbol{A}$, The diagram on the left illustrates the recording configuration. Middle, Representative time courses of EPSCs in both saline-injected (open symbols) and METH-injected (filled symbols) mice of group $2 \mathrm{GFP}^{+}$cells. Insets, Representative 60 traces (gray lines) and their average (black lines) before (1) and $\sim 40$ min after (2) TBS (arrow). B, Population time course of group 2 DGC plasticity. C, LTP magnitude assessed after $\sim 40$ min (2) normalized to baseline (1) in group 2 DG neurons. $\boldsymbol{D}-\boldsymbol{F}$, As in $\boldsymbol{A}-\boldsymbol{C}$, but for group 3 cells. $\mathbf{G}-\boldsymbol{I}$, as in $\boldsymbol{A}-\boldsymbol{C}$ and $\boldsymbol{D}-\boldsymbol{F}$, but for mature, GFP DGCs. Data are expressed as the mean \pm SEM. $* p<0.05, * * p<0.01$, and $* * * p<0.001$, significantly different from baseline using the Mann-Whitney post hoc test. $\S p<0.05$, $\S \S p<0.01$, significantly different from saline, using the Mann-Whitney post hoc test.

GFP), TBS application increased EPSC amplitude in both the saline group (baseline, $138.90 \pm 18.44 \mathrm{pA}$; last $5 \mathrm{~min}$ after TBS, $191.10 \pm 28.50 \mathrm{pA} ; p<0.05$, paired $t$ test; $n=$ 12 cells; Fig. 2G) and the METH group (baseline, $128.20 \pm$ $15.75 \mathrm{pA}$; last 5 min after TBS, $234.90 \pm 23.35 \mathrm{pA} ; p<$ 0.001 , paired $t$ test; $n=10$; Fig. $2 G$ ). Remarkably, however, METH strengthened LTP significantly compared with saline $(p<0.05$; Fig. $2 H, I)$.

Overall, long-term METH treatment did not interfere with synaptic plasticity in more immature DGCs (group 2 $\mathrm{GFP}^{+}$neurons), but it promoted and enhanced LTP at more differentiated stages (group $3 \mathrm{GFP}^{+}$neurons) and in fully developed $\mathrm{GFP}^{-}$neurons.

\section{Methamphetamine treatment did not change DGC dendritic morphology}

The METH-induced effects on synaptic plasticity in DGCs could be accompanied by morphological changes of DGCs. We then tested whether long-term exposure to METH induced dendritic alterations at different differentiation stages. We filled $\mathrm{GFP}^{+}$neurons from the three groups with neurobiotin and analyzed their dendritic morphology. Group 1 cells showed few and short ramifications, and cell bodies were mostly confined in the inner dentate granule layer (Fig. 3A). Complexity was more prominent as $\mathrm{GFP}^{+}$DGCs belonged to groups 2 and 3, which gradually acquired the typical morphology of ma- 
A

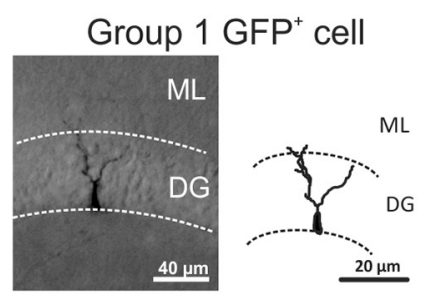

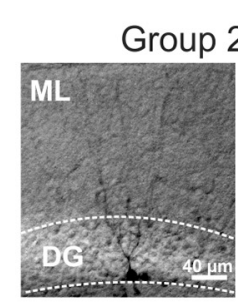

B

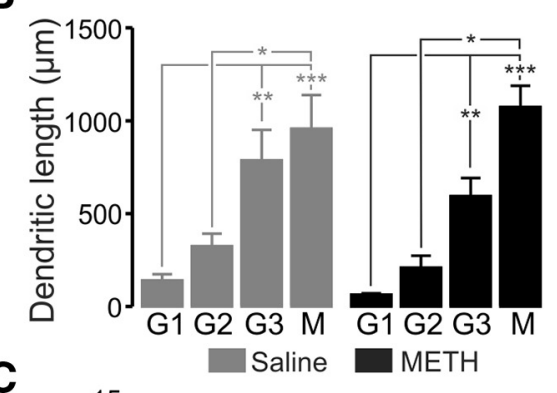

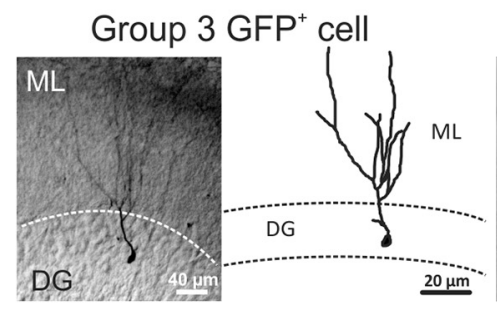
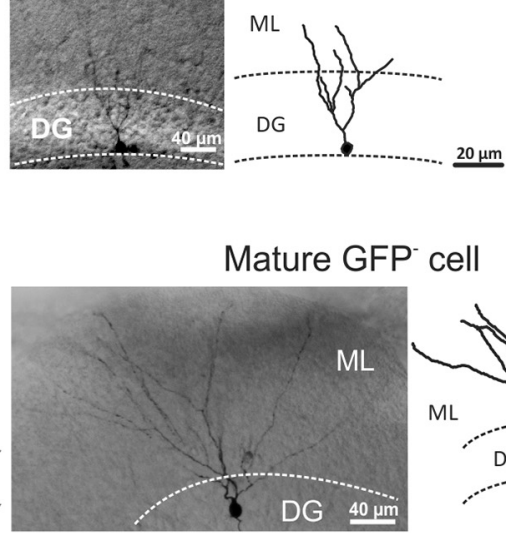

$2 \mathrm{GFP}^{+}$cell

Figure 3. DG immature neurons exhibit different morphologies. $\boldsymbol{A}$, Example micrographs of neurobiotin-filled DGCs of all groups (left) and their digital reconstructions (right). $\boldsymbol{B}, \boldsymbol{C}$, Bar graphs representing the total dendritic length (B) and the number of dendritic terminals $(\boldsymbol{C})$ of $\mathrm{GFP}^{+}$and mature DGCs, showing no effect of METH. Data are expressed as the mean \pm SEM from at least four mice. $* p<0.05, * * p<0.01$, and $* * * p<0.001$, significantly different using the Kruskal-Wallis test followed by Dunn's post hoc test. G1, Group $1 \mathrm{GFP}^{+}$cells; G2, group $2 \mathrm{GFP}^{+}$cells; G3, group $3 \mathrm{GFP}^{+}$cells; M, mature DGCs.

ture DGCs (Fig. 3A). These changes were statistically significant across different DG groups in both saline- and METH-treated animals. Overall, METH administration did not produce any effect on dendritic length (group 1: 63.62 \pm 7.363 vs $140.40 \pm 33.43 \mu \mathrm{m}, n=5$ vs $n=10$; group 2 : $208.40 \pm 65.26$ vs $323.10 \pm 69.17 \mu \mathrm{m}, n=5$ vs $n=11$; group 3: $592.80 \pm 98.90$ vs $786.20 \pm 164.60 \mu \mathrm{m}, n=10$ vs $n=6$ ); mature: $1073.00 \pm 115.60$ vs $956.60 \pm 181.60$ $\mu \mathrm{m}, n=13$ vs $n=9$; METH vs saline, respectively, $p>$ 0.05 in all cases; Fig. 3B). Similarly, METH did not change the number of dendritic terminals (group 1: $2.40 \pm 0.51$ vs $2.90 \pm 0.62, n=5$ vs $n=10$; group $2: 2.50 \pm 0.29$ vs 3.82 $\pm 0.42, n=5$ vs $n=11$; group $3: 7.00 \pm 0.77$ vs $6.83 \pm$ $1.25, n=10$ vs $n=6$; mature: $9.15 \pm 0.60$ vs $8.33 \pm 1.04$, $n=13$ vs $n=9$; METH vs saline, respectively, $p>0.05$; Fig. 3C).

As a result, METH treatment did not produce any effect on DGC dendritic morphology with respect to either the dendritic length or on the number of dendritic terminals.

Methamphetamine enhances the enlargement of dendritic spines on both group 2 and group $3 \mathrm{GFP}^{+}$cells

DGC dendritic spines are the major postsynaptic sites of glutamatergic inputs from the entorhinal cortex (Colino and Malenka, 1993). Changes in spine density and morphology are associated with and can contribute to LTP (Ohkawa et al., 2012). We therefore examined whether METH-induced strengthening of LTP was associated with a consistent change in DGC spine morphology. No dendritic spines could be observed in group $1 \mathrm{GFP}^{+}$cells (data not shown), whereas they could be detected in group 2 and group 3 cells (Fig. 4A). Spine density was assessed in $\mathrm{GFP}^{+}$cells in both groups 2 and 3 , as well as in mature neurons under saline and METH conditions (Fig. $4 B)$. Spine density significantly increased with DGC mat- uration, reaching a mature level in stage $3 \mathrm{GFP}^{+}$neurons, as it was not different from that seen in $\mathrm{GFP}^{-}$cells. We found that METH did not induce alterations in spine density in all groups (group 2: $0.18 \pm 0.06$ vs $0.23 \pm 0.05 \mu \mathrm{m}$, $n=7$ vs $n=11$; Group 3: $0.52 \pm 0.07$ vs $0.58+0.09 \mu \mathrm{m}$, $n=7$ vs $n=9$; mature: $0.63+0.07$ vs $0.52 \pm 0.05 \mu \mathrm{m}$, $n=14$ vs $n=11$; METH vs saline, respectively, $p>0.05$ in all groups; Fig. 4B). Interestingly, however, we observed that METH treatment induced an overall significant increase in spine area in GFP ${ }^{+}$DGCs belonging to group $2(n=115$ in saline and $n=59$ in METH) and group 3 ( $n$ $=228$ in saline and $n=189$ in METH; $p<0.001$; Fig. $4 C, D)$. This effect was seen only in $\mathrm{GFP}^{+}$differentiating neurons, and not in mature (GFP ${ }^{-}$) DGCs, where a small (albeit significant; $p<0.001)$ reduction was present $(n=$ 526 in saline and $n=479$ in METH; Fig. 4E).

Overall, these results suggest that METH treatment affected spine morphology, but not density, in maturing DGCs.

\section{Discussion}

In the present study, we show that repetitive administration of low doses of METH to G42 mice enhanced the differentiation of immature DGCs, induced an enlargement of dendritic spines in differentiating $\mathrm{GFP}^{+}$cells, and facilitated LTP in more mature $\mathrm{GFP}^{+}$as well as in mature DGCs.

We used GFP-expressing neurons in G42 mice, which have been demonstrated to be a useful tool with which to study the functional and anatomical phenotypes of differentiating DGCs (Cabezas et al., 2012; 2013). In this mouse line, GFP expression is transiently expressed in postmitotic DGCs, displaying some aspects of a GABAergic phenotype (Cabezas et al., 2012, 2013). Here we found 

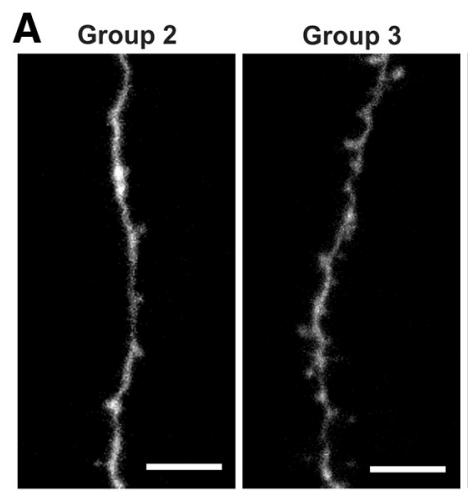

Croup 2
GFP $^{+}$cell
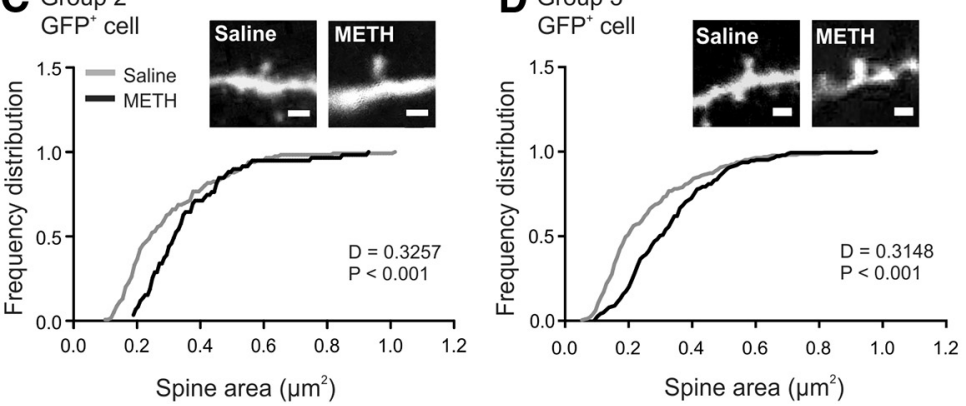

B
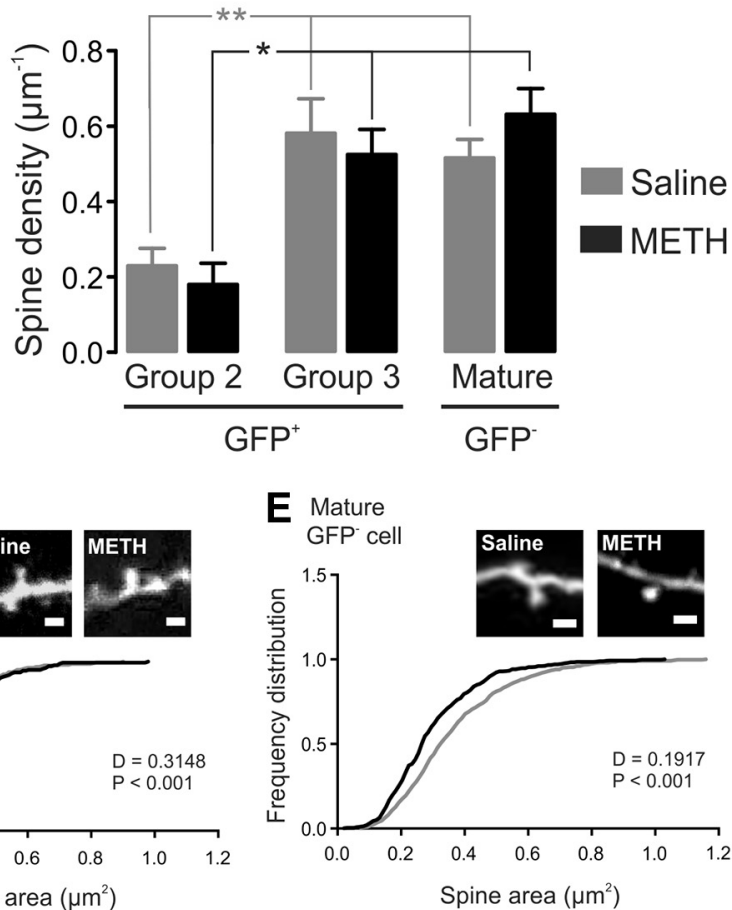

Figure 4. METH effects on spine areas in immature and mature DGCs. $\boldsymbol{A}$, Representative confocal images of dendritic spines of group 2 and $3 \mathrm{GFP}^{+}$cells and mature neurons. Scale bar, $5 \mu \mathrm{m}$. B, Bar graph depicting spine density in immature and mature DGCs. $\boldsymbol{C}-\boldsymbol{E}$, Distribution graph of spine area quantified from group $2(\boldsymbol{C})$ as well as in group $3(\boldsymbol{D}) \mathrm{GFP}^{+}$cells and mature DGCs $(\boldsymbol{E}) . * p<0.05$, $* * p<0.01$, and $* * * p<0.001$, significantly different using the Kruskal-Wallis test followed by Dunn's post hoc test. Cumulative distributions were compared using Kolmogorov-Smirnov test. Scale bar, $1 \mu \mathrm{m}$.

that METH did not change the total number of GFP neurons, suggesting that METH can promote the differentiation of immature neurons. Indeed, METH decreased the number of $\mathrm{GFP}^{+}$neurons expressing DCX and increased those expressing NeuN without changing the overall fraction of GFP cells coexpressing DCX and NeuN. This could be explained by an acceleration of neuronal maturation. Indeed, the maturation of DG neurons is a dynamic process: $\mathrm{DCX}^{+}$neurons also start expressing NeuN $\left(\mathrm{DCX}^{+} \mathrm{NeuN}^{+}\right)$and then stop expressing DCX, expressing NeuN alone (Cabezas et al., 2013). If METH accelerates both these transitions, the intermediate, timefixed $\mathrm{DCX}^{+} \mathrm{NeuN}^{+}$phase will be unchanged, because the increased appearance of "early" DCX ${ }^{+} \mathrm{NeuN}^{+}$cells balances out the increased disappearance of "late" $\mathrm{DCX}^{+} \mathrm{NeuN}^{+}$neurons, with a net zero effect. This is supported by the evidence that METH treatment induced a significant decrease of the total fraction of $\mathrm{DCX}^{+}$cells (regardless of whether they also expressed NeuN) and an overall increase of $\mathrm{NeuN}^{+}$cells (regardless of whether they also expressed DCX). Importantly, the METHinduced acceleration of immature neurons is in line with the findings of a previous report (Mandyam et al., 2008) showing the induction of DGC maturation in rats selfadministering $M E T H$, resulting in an increased population of neurons differentiated from progenitor cells. GFP ${ }^{+}$cells encompassed a mix of differentiating stages, including an early one (defined as group 1) in which neurons expressed both DCX and NeuN; had limited dendritic branching and spine density; and were characterized by immature firing, high-input resistance, and lack of impinging glutamatergic synaptic transmission. This was likely due to dendrites not reaching the middle molecular layer, and therefore not receiving input from the MPP, indicating that group 1 $\mathrm{GFP}^{+}$cells were not fully integrated into DG circuits yet. We observed that $\sim 40 \%$ of GFP cells expressed only DCX; however, we did not find cells exclusively expressing DCX when we correlated the immunohistochemical phenotype of the $\mathrm{GFP}^{+}$phenotype with their firing. This was probably due to the low number of neurons belonging to group 1 during electrophysiological recordings coupled to immunohistochemistry ( $n=9$ of 36 neurons recorded in total). It is likely that group 1 cells encompass neurons expressing DCX only and DCX and NeuN, representing early maturing neurons. Overall, group 1 neurons likely correspond to an early postmitotic stage (Kempermann et al., 2004; Overstreet-Wadiche and Westbrook, 2006), between 15 and $19 \mathrm{~d}$ of age (Zhao et al., 2006; Mongiat et al., 2009; Cabezas et al., 2013). In addition to these early-stage neurons, $\mathrm{GFP}^{+}$cells included NeuN-expressing neurons, which could (group 3) or could not (group 2) fire high-amplitude APs repetitively, and showed increasingly more complex dendritic arborization and higher spine density. Group 2 cells are likely in their third week of age (21-25 d old) as they show reliable EPSCs in response to MPP stimulation (Mongiat et al., 2009), and, 
in line with other studies (Ge et al., 2007), they showed robust plasticity. Group 3 cells have a mature-like AP firing and longer dendrites that, compared with retroviralmediated labeling of immature neurons, resemble 28- $d-$ old neurons (Zhao et al., 2006; Mongiat et al., 2009). These neurons responded to TBS with a medium-term $(<20 \mathrm{~min})$ potentiation that did not consistently develop into a longer-lasting LTP. This could be due to a different LTP threshold for specific TBS patterns on DGCs at specific developmental stages (Schmidt-Hieber et al., 2007) or differential GluN2B expression during maturation, a process that is necessary for enhanced plasticity $(\mathrm{Ge}$ et al., 2007). Moreover, the lack of sustained plasticity might be representative of this class of $\mathrm{GFP}^{+}$cells, which can include a subtype of immature DGC with specific synaptic and/or plasticity features.

We found that METH treatment promoted synaptic plasticity in more differentiated neurons, inducing LTP in group 3 neurons, which could not sustain persistent potentiation in control conditions, and it enhanced the plasticity of mature DGCs. Interestingly, this effect was specific for more differentiated neurons, whereas plasticity in more immature group 2 neurons was unaffected by METH treatment. This could be ascribed to different mechanisms governing the plasticity of DGCs at different developmental stages, of which only the more mature ones may be sensitive to METH. Alternatively, more immature neurons attain an already high plasticity level that could not be potentiated further, corresponding to the peak of their critical period (Ge et al., 2007).

METH-dependent effects on spine areas was more pronounced in DGCs in groups 2 and 3, and had a smaller, opposite effect in GFP ${ }^{-}$mature neurons, which is in line with previous evidence indicating that LTP promotes spine enlargement in DG immature neurons (Ohkawa et al., 2012).

Overall, however, our results in $\mathrm{GFP}^{+}$differentiating and GFP $^{-}$mature DGCs suggest that METH-induced effects on LTP might or might not be directly related with those on spine morphology, possibly due to the direct effect on NMDARs, as these receptors have been shown to play a fundamental role in governing plasticity-dependent alterations of spine morphology (Matsuzaki et al., 2004; Zhou et al., 2004; Mahmmoud et al., 2015), and METH treatment was shown to enhance NMDAR mobility (Yamamoto et al., 2006). Alternatively, they might be ascribed to complex interactions between specific DA receptors and NMDARs at different stages of DGC differentiation (Yamamoto et al., 2006; Nai et al., 2010; Yang and Dani, 2014). Future experiments will be required to determine the cellular mechanisms underlying LTP enhancement by METH at specific differentiating stages of DGCs.

Long-term plasticity of hippocampal glutamatergic synapses is believed to be the cellular mechanism of learning and memory (Zeng et al., 2001; Whitlock et al., 2006; Nabavi et al., 2013, 2014; Gruart et al., 2015; Ryan et al., 2015), and it has been shown that a decrease in the plasticity of glutamatergic synapses onto DGCs has a negative effect in memory performance tasks (Farioli-Vecchioli et al., 2008). A specific METH dose and exposure time may induce differ- ential changes at these synapses, affecting both glutamate receptor subunits and glutamate release (Simões et al., 2007; Baptista et al., 2012). It is thus tempting to speculate that the enhanced LTP following METH administration may result in improved memory. In addition to its known recreational use, METH is also prescribed for ADHD treatment, at a usual effective dose of $20-25 \mathrm{mg}$ daily, which is similar to the dose administered to mice in the present study. Importantly, due to its addictive properties, METH is usually prescribed for short periods of time. Individuals in whom ADHD is diagnosed display several aspects of behavior, including hyperactivity, decreased sustained attention, increased behavior variability, and decreased DA transmission (for review, see Himelstein et al., 2000). METH is used to enhance dopaminergic transmission in order to attenuate the symptoms mentioned above, but it may induce dependence, as shown in ADHD animal models (dela Peña et al., 2012).

In conclusion, the present work shows that long-term administration with a low dose of METH promoted the differentiation of immature neurons and enhanced LTP in differentiating and mature DGCs. It will be fundamental to understand how prolonged use of METH will convert such "positive" effects on neurogenesis and synaptic plasticity into the well known dysfunctional effects that strongly impair cognitive performance in METH-addicted subjects.

\section{References}

Baptista S, Bento AR, Gonçalves J, Bernardino L, Summavielle T, Lobo A, Fontes-Ribeiro C, Malva JO, Agasse F, Silva AP (2012) Neuropeptide $Y$ promotes neurogenesis and protection against methamphetamine-induced toxicity in mouse dentate gyrusderived neurosphere cultures. Neuropharmacology 62:2413-2423. CrossRef Medline

Baptista S, Lasgi C, Benstaali C, Milhazes N, Borges F, Fontes-Ribeiro C, Agasse F, Silva AP (2014) Methamphetamine decreases dentate gyrus stem cell self-renewal and shifts the differentiation towards neuronal fate. Stem Cell Res 13:329-341. CrossRef Medline

Bliss TV, Lømo T (1973) Long-lasting potentiation of synaptic transmission in the dentate area of the anaesthetized rabbit following stimulation of the perforant path. J Physiol 232:331-356. Medline

Bowden JB, Abraham WC, Harris KM (2012) Differential effects of strain, circadian cycle, and stimulation pattern on LTP and concurrent LTD in the dentate gyrus of freely moving rats. Hippocampus 22:1363-1370. CrossRef Medline

Cabezas C, Irinopoulou T, Gauvain G, Poncer JC (2012) Presynaptic but not postsynaptic GABA signaling at unitary mossy fiber synapses. J Neurosci 32:11835-11840. CrossRef Medline

Cabezas C, Irinopoulou T, Cauli B, Poncer JC (2013) Molecular and functional characterization of GAD67-expressing, newborn granule cells in mouse dentate gyrus. Front Neural Circuits 7:60. CrossRef Medline

Cao G, Zhu J, Zhong Q, Shi C, Dang Y, Han W, Liu X, Xu M, Chen T (2013) Distinct roles of methamphetamine in modulating spatial memory consolidation, retrieval, reconsolidation and the accompanying changes of ERK and CREB activation in hippocampus and prefrontal cortex. Neuropharmacology 67:144-154. CrossRef Medline

Chattopadhyaya B, Di Cristo G, Higashiyama H, Knott GW, Kuhlman SJ, Welker E, Huang ZJ (2004) Experience and activity-dependent maturation of perisomatic GABAergic innervation in primary visual cortex during a postnatal critical period. J Neurosci 24:9598-9611. CrossRef Medline

Chiu CQ, Castillo PE (2008) Input-specific plasticity at excitatory synapses mediated by endocannabinoids in the dentate gyrus. Neuropharmacology 54:68-78. CrossRef Medline 
Colino A, Malenka RC (1993) Mechanisms underlying induction of long-term potentiation in rat medial and lateral perforant paths in vitro. J Neurophysiol 69:1150-1159. Medline

dela Peña I, Lee JC, Lee HL, Woo TS, Lee HC, Sohn AR, Cheong JH (2012) Differential behavioral responses of the spontaneously hypertensive rat to methylphenidate and methamphetamine: lack of a rewarding effect of repeated methylphenidate treatment. Neurosci Lett 514:189-193. CrossRef Medline

Farioli-Vecchioli S, Saraulli D, Costanzi M, Pacioni S, Cinà I, Aceti M, Micheli L, Bacci A, Cestari V, Tirone F (2008) The timing of differentiation of adult hippocampal neurons is crucial for spatial memory. PLoS Biol 6:e246. CrossRef Medline

Garthe A, Behr J, Kempermann G (2009) Adult-generated hippocampal neurons allow the flexible use of spatially precise learning strategies. PLoS One 4:e5464. CrossRef Medline

Ge S, Yang CH, Hsu KS, Ming GL, Song H (2007) A critical period for enhanced synaptic plasticity in newly generated neurons of the adult brain. Neuron 54:559-566. CrossRef Medline

Gonçalves J, Baptista S, Olesen MV, Fontes-Ribeiro C, Malva JO, Woldbye DP, Silva AP (2012) Methamphetamine-induced changes in the mice hippocampal neuropeptide $Y$ system: implications for memory impairment. J Neurochem 123:1041-1053. CrossRef Medline

Gonçalves J, Baptista S, Silva AP (2014) Psychostimulants and brain dysfunction: a review of the relevant neurotoxic effects. Neuropharmacology 87:135-149.

Gruart A, Leal-Campanario R, López-Ramos JC, Delgado-García JM (2015) Functional basis of associative learning and their relationships with long-term potentiation evoked in the involved neural circuits: lessons from studies in behaving mammals. Neurobiol Learn Mem 124:3-18. CrossRef Medline

Hargreaves EL, Rao G, Lee I, Knierim JJ (2005) Major dissociation between medial and lateral entorhinal input to dorsal hippocampus. Science 308:1792-1794. CrossRef Medline

Himelstein J, Newcorn JH, Halperin JM (2000) The neurobiology of attention-deficit hyperactivity disorder. Front Biosci 5:D461-D478.

Kee N, Teixeira CM, Wang AH, Frankland PW (2007) Preferential incorporation of adult-generated granule cells into spatial memory networks in the dentate gyrus. Nat Neurosci 10:355-362. CrossRef Medline

Kempermann G, Jessberger S, Steiner B, Kronenberg G (2004) Milestones of neuronal development in the adult hippocampus. Trends Neurosci 27:447-452. CrossRef Medline

Lledo PM, Alonso M, Grubb MS (2006) Adult neurogenesis and functional plasticity in neuronal circuits. Nat Rev Neurosci 7:179_ 193. CrossRef Medline

Malinow R, Malenka RC (2002) AMPA receptor trafficking and synaptic plasticity. Annu Rev Neurosci 25:103-126. CrossRef Medline

Mandyam CD, Wee S, Crawford EF, Eisch AJ, Richardson HN, Koob GF (2008) Varied access to intravenous methamphetamine selfadministration differentially alters adult hippocampal neurogenesis. Biol Psychiatry 64:958-965. CrossRef Medline

Mahmmoud RR, Sase S, Aher YD, Sase A, Gröger M, Mokhtar M, Höger H, Lubec G (2015) Spatial and working memory is linked to spine density and mushroom spines. PLoS One 10:e0139739. CrossRef Medline

Matsuzaki M, Honkura N, Ellis-Davies GC, Kasai H (2004) Structural basis of long-term potentiation in single dendritic spines. Nature 429:761-766. CrossRef Medline

Mongiat LA, Espósito MS, Lombardi G, Schinder AF (2009) Reliable activation of immature neurons in the adult hippocampus. PLoS One 4:e5320. CrossRef Medline

Nabavi S, Fox R, Alfonso S, Aow J, Malinow R (2013) GluA1 trafficking and metabotropic NMDA: addressing results from other laboratories inconsistent with ours. Philos Trans $\mathrm{R}$ Soc Lond B Biol Sci 369:20130145. CrossRef Medline

Nabavi S, Fox R, Proulx CD, Lin JY, Tsien RY, Malinow R (2014) Engineering a memory with LTD and LTP. Nature 511:348-352. CrossRef Medline
Nai Q, Li S, Wang SH, Liu J, Lee FJ, Frankland PW, Liu F (2010) Uncoupling the D1-N-methyl-D-aspartate (NMDA) receptor complex promotes NMDA-dependent long-term potentiation and working memory. Biol Psychiatry 67:246-254. CrossRef Medline

Nakashiba T, Cushman JD, Pelkey KA, Renaudineau S, Buhl DL, McHugh TJ, Rodriguez Barrera V, Chittajallu R, Iwamoto KS, McBain CJ, Fanselow MS, Tonegawa S (2012) Young dentate granule cells mediate pattern separation, whereas old granule cells facilitate pattern completion. Cell 149:188-201. CrossRef Medline

Ohkawa N, Saitoh Y, Tokunaga E, Nihonmatsu I, Ozawa F, Murayama A, Shibata F, Kitamura T, Inokuchi K (2012) Spine formation pattern of adult-born neurons is differentially modulated by the induction timing and location of hippocampal plasticity. PLoS One 7:e45270. CrossRef Medline

Overstreet-Wadiche LS, Westbrook GL (2006) Functional maturation of adult-generated granule cells. Hippocampus 16:208-215. CrossRef Medline

Panja D, Kenney JW, D'Andrea L, Zalfa F, Vedeler A, Wibrand K, Fukunaga R, Bagni C, Proud CG, Bramham CR (2014) Two-stage translational control of dentate gyrus LTP consolidation is mediated by sustained BDNF-TrkB signaling to MNK. Cell Rep 9:14301445. CrossRef Medline

Richter-Levin G, Errington ML, Maegawa H, Bliss TV (1994) Activation of metabotropic glutamate receptors is necessary for longterm potentiation in the dentate gyrus and for spatial learning. Neuropharmacology 33:853-857. Medline

Ryan TJ, Roy DS, Pignatelli M, Arons A, Tonegawa S (2015) Memory Engram cells retain memory under retrograde amnesia. Science 348:1007-1013. CrossRef Medline

Schmidt-Hieber C, Jonas P, Bischofberger J (2007) Subthreshold dendritic signal processing and coincidence detection in dentate gyrus granule cells. J Neurosci 27:8430-8441. CrossRef

Silber BY, Croft RJ, Papafotiou K, Stough C (2006) The acute effects of $\mathrm{d}$-amphetamine and methamphetamine on attention and psychomotor performance.Psychopharmacology (Berl) 187:154-169.

Simões PF, Silva AP, Pereira FC, Marques E, Grade S, Milhazes N, Borges F, Ribeiro CF, Macedo TR (2007) Methamphetamine induces alterations on hippocampal NMDA and AMPA receptor subunit levels and impairs spatial working memory. Neuroscience 150:433-441. CrossRef Medline

Simon SL, Domier C, Carnell J, Brethen P, Rawson R, Ling W (2000) Cognitive impairment in individuals currently using methamphetamine. Am J Addict 9:222-231. Medline

Thompson PM, Hayashi KM, Simon SL, Geaga JA, Hong MS, Sui Y, Lee JY, Toga AW, Ling W, London ED (2004) Structural abnormalities in the brains of human subjects who use methamphetamine. J Neurosci 24:6028-6036. CrossRef Medline

Whitlock JR, Heynen AJ, Shuler MG, Bear MF (2006) Learning induces long-term potentiation in the hippocampus. Science 313: 1093-1097. CrossRef Medline

Yamamoto H, Imai K, Kamegaya E, Takamatsu Y, Irago M, Hagino Y, Kasai S, Shimada K, Yamamoto T, Sora I, Koga H, Ikeda K (2006) Repeated methamphetamine administration alters expression of the NMDA receptor channel epsilon2 subunit and kinesins in the mouse brain. Ann N Y Acad Sci 1074:97-103. CrossRef

Yang K, Dani JA (2014) Dopamine D1 and D5 receptors modulate spike timing-dependent plasticity at medial perforant path to dentate granule cell synapses. J Neurosci 34:15888-15897. CrossRef Medline

Zeng H, Chattarji S, Barbarosie M, Rondi-Reig L, Philpot BD, Miyakawa T, Bear MF, Tonegawa S (2001) Forebrain-specific calcineurin knockout selectively impairs bidirectional synaptic plasticity and working/episodiclike memory. Cell 107:617-629. Medline

Zhao C, Teng EM, Summers RG Jr, Ming GL, Gage FH (2006) Distinct morphological stages of dentate granule neuron maturation in the adult mouse hippocampus. J Neurosci 26:3-11. CrossRef Medline

Zhou Q, Homma KJ, Poo MM (2004) Shrinkage of dendritic spines associated with long-term depression of hippocampal synapses. Neuron 44:749-757. CrossRef Medline 